\title{
Extrusion of YAG Tubes Shows that Bottom-up Processing is Not Always Optimal
}

\author{
Nathan J. Taylor and Richard M. Laine*
}

Liquid-feed flame spray pyrolysis provides easily dispersed, unaggregated nanopowders with average particle sizes of 20-70 $\mathrm{nm}$ depending on the processing conditions. Their chemical compositions can be controlled to ppm levels via control of the initial precursor solution. In this paper, $\mathrm{Y}_{3} \mathrm{Al}_{5} \mathrm{O}_{12}$ composition nanopowders are produced that are atomically mixed but offer a hexagonal crystal structure rather than a YAG structure. $\mathrm{Y}_{2} \mathrm{O}_{3}$ and $\delta-\mathrm{Al}_{2} \mathrm{O}_{3}$ nanopowders are also produced and mixed to evaluate reactive sintering. It is shown that nanopowder/polymer mixtures permit the extrusion of tubes that retain their shape on debindering and sintering to $\geq 95 \%$ theoretical density. More importantly, the sintering behavior of hex- $\mathrm{Y}_{3} \mathrm{Al}_{5} \mathrm{O}_{12}$ is compared with that of tubes formed using 3:5 $\mathrm{Y}_{2} \mathrm{O}_{3}: \delta-\mathrm{Al}_{2} \mathrm{O}_{3}$ mixtures to test the so-called bottom-up paradigm, which suggests that mixing on the finest length scales should provide optimal control of sintering rates, final densities, and grain sizes. Instead, it is found that reactive sintering is faster and offers better control of final grain sizes. Dense sintered tubes are translucent, and dimensional uniformity is maintained from extrusion through sintering.

\section{Introduction}

There is a considerable driving force to develop highly transmissive materials for high-temperature transparent ceramics for applications ranging from armor to lasers, to sodium vapor lamp envelopes. ${ }^{[1]}$ The current material of choice for armor and lamp envelopes is $\alpha-\mathrm{Al}_{2} \mathrm{O}_{3}$, whereas doped YAG has emerged as the material of choice for lasers. ${ }^{[2-5]}$ While widely used, polycrystalline $\alpha-\mathrm{Al}_{2} \mathrm{O}_{3}$ has significant optical losses due to its inherent birefringence. ${ }^{[5]}$ As such, it is limited to translucent applications (as in vapor lamp envelopes, with average grain sizes of $20^{+} \mu \mathrm{m}$ ) or transparent applications where grain sizes are sub-500 nm, typically attained only by hot isostatic pressing (HIPping) for long periods of time $\left(12 \mathrm{~h}, 200 \mathrm{MPa}, 1250^{\circ} \mathrm{C}\right) . .^{[2]}$

Polycrystalline YAG is a potential replacement material for polycrystalline $\alpha-\mathrm{Al}_{2} \mathrm{O}_{3}$ due to its high transparency in the visible region, along with satisfactory thermal shock and chemical resistance. ${ }^{[1,4]}$ In most applications, polycrystalline YAG is sintered at temperatures of $1700-1800{ }^{\circ} \mathrm{C}$ in vacuum, taking advantage of excessive grain growth to limit porosity and grain

N. J. Taylor, Prof. R. M. Laine

Department of Materials Science and Engineering

University of Michigan

Ann Arbor, MI, 48109-2136, USA

E-mail: talsdad@umich.edu

DOI: $10.1002 / \mathrm{adfm} .201301290$ boundary light scattering, but at the cost of both mechanical and optical properties. ${ }^{[6]}$ YAG nanopowders are often made via solution-based processes, although reactive sintering of $\mathrm{Y}_{2} \mathrm{O}_{3}$ and $\mathrm{Al}_{2} \mathrm{O}_{3}$ powders also appears to be a viable route to high-quality YAG monoliths. ${ }^{[7]}$

Most laser-quality ceramic YAG is either cold pressed or slip cast to form green bodies, which limits attainable geometries. ${ }^{[8,9]}$ Thermoplastic extrusion is an attractive candidate for producing more complex shapes, with the drawback of much lower green densities than are accessible via cold-pressing or slip casting. ${ }^{10]}$ The production of near-net shape ceramic monoliths is especially crucial in optical ceramics, where expensive and time-consuming machining and polishing operations could be reduced. In addition, many demanding applications for transparent ceramics, such as missile radomes, have complicated geometries. Thermoplastic extrusion of nanopowders has rarely been studied, likely due to the challenges in obtaining high solids loadings due to the increased surface area interactions between particles in the melt, leading to extremely high viscosities that prevent easy extrusion. ${ }^{[11,12]}$

Liquid-feed flame spray pyrolysis (LF-FSP) is a unique route to mixed-metal oxide nanopowders with elemental mixing at the atomic level. ${ }^{[13,14]}$ In LF-FSP, ethanol solutions of metalloorganic precursors are combusted, producing nanopowder "soot" with average particle sizes (APSs) of 25-70 $\mathrm{nm}$. The asproduced powders are unaggregated but lightly agglomerated. In principal, these powders offer the potential to sinter to high densities at low temperatures, with exceptional control of final grain sizes and, according the bottom-up paradigm, should permit ready optimization of final global properties including, for example, optical properties.

Indeed, the "bottom-up" approach to processing materials has received considerable support from numerous research groups in the past few years. ${ }^{[15-22]}$ However, to the best of our knowledge, no one has sought to test this concept. Thus, one major objective of the work reported here is to attempt to validate this axiom. In an upcoming paper, we will discuss this approach to dense $\mathrm{NiAl}_{2} \mathrm{O}_{4} / \alpha-\mathrm{Al}_{2} \mathrm{O}_{3}$ composites from both atomically mixed metastable nanopowders and mixed nanopowders of the constituent oxides.

LF-FSP has been used previously to produce $\mathrm{Y}_{3} \mathrm{Al}_{5} \mathrm{O}_{12} \mathrm{com}$ position nanopowders albeit generating a hexagonal phase 
that transforms to YAG with a low activation energy, referred to hereafter as hex$\mathrm{Y}_{3} \mathrm{Al}_{5} \mathrm{O}_{12} \cdot{ }^{[23,24]}$ In the work reported here, we explored the utility of using this atomically mixed, single-phase material as the basis for extruding tubes with the long term goal of making them transparent.

As part of this work, we also evaluated the maxim that optimal control of the scale of elemental mixing should provide the best control of sintering rates, final grain sizes, and final densities. Thus, comparative studies using 3:5 molar mixtures of $\mathrm{Y}_{2} \mathrm{O}_{3}: \delta-\mathrm{Al}_{2} \mathrm{O}_{3}$ were undertaken in an effort to process tubes using reactive sintering. In this case, both

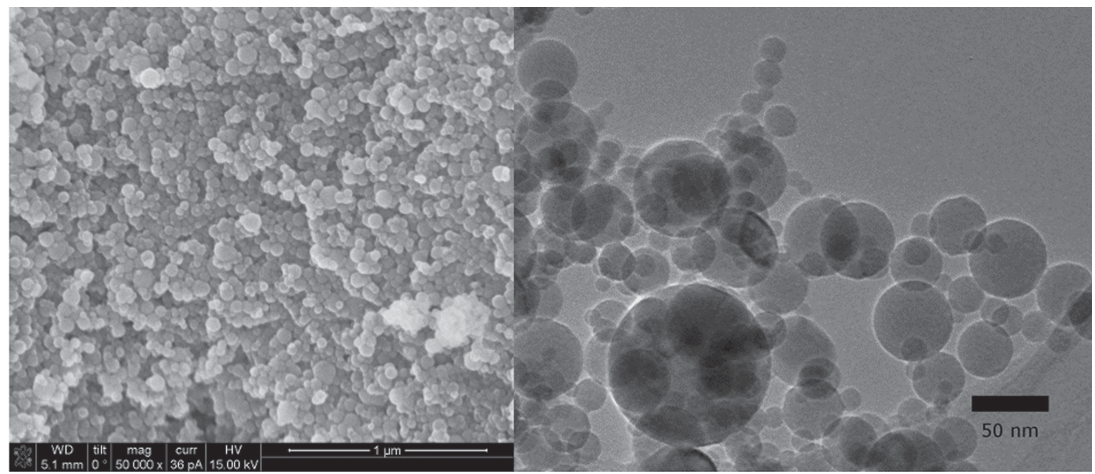

Figure 1. a) SEM and b) TEM images of LF-FSP-produced $\mathrm{Y}_{3} \mathrm{Al}_{5} \mathrm{O}_{12}$ powders. oxide nanopowders (APSs 30-40 nm) were mixed and then ball milled, achieving what we estimate to be compositonal homogeneity at the submicrometer scale at best.

Both sets of powders were thereafter mixed with an ethylene vinyl acetate polymer binder in a Brabender shear mixer and then thermoplastically extruded. Both approaches produced $10 \mathrm{~mm}$ diameter tubes with $0.7 \mathrm{~mm}$ wall thicknesses, up to $1 \mathrm{~m}$ in length. Ten centimeter sections were sintered to at least $95 \%$ theoretical density (TD) with grain sizes of $0.5-3 \mu \mathrm{m}$. Surprisingly, nanosized $\mathrm{Y}_{2} \mathrm{O}_{3}$ and $\mathrm{Al}_{2} \mathrm{O}_{3}$ powders reactively sinter at lower temperatures and to finer final grain sizes than the YAG composition powders. This contrasts strongly with the commonly accepted maxim of "finer mixing is better."

\section{Results and Discussion}

In the following sections, characterization of the powders used in tube processing is presented, followed by a discussion of the tube extrusion, binder burnout, and final densification. Thereafter, the processes that occur leading to faster densification for the reactive sintered powders than the stoichiometrically correct single-phase powders are discussed.

\subsection{Powder Characterization}

Table 1 records the BET-derived specific surface area analysis (SSA) results and the corresponding calculated APSs for the LF-FSP and commercial nanopowders used in this study. $\mathrm{Y}_{3} \mathrm{Al}_{5} \mathrm{O}_{12}$ composition nanopowders produced by LF-FSP are a hexagonal phase, as described previously and confirmed by X-ray diffraction (XRD). ${ }^{[24]}$ Figure 1 provides scanning electron microscope (SEM) and transmission electron microscope (TEM) images representative of hex- $\mathrm{Y}_{3} \mathrm{Al}_{5} \mathrm{O}_{12}$ composition powders. Figure 2 provides an SEM images representative of the LF-FSP

Table 1. BET SSAs, and corresponding APSs, assuming spherical particles.

\begin{tabular}{lccc}
\hline & $\mathrm{Al}_{2} \mathrm{O}_{3}$ & $\mathrm{Y}_{2} \mathrm{O}_{3}$ & $\mathrm{Y}_{3} \mathrm{Al}_{5} \mathrm{O}_{12}$ \\
\hline BET SSA $\left[\mathrm{m}^{2} \mathrm{~g}^{-1}\right]$ & 30 & 30 & 36 \\
APS $[\mathrm{nm}]$ & 56 & 40 & 37 \\
\hline
\end{tabular}

$\mathrm{Y}_{2} \mathrm{O}_{3}$ powders. The SEM images show uniform particles with typical APSs $<50 \mathrm{~nm}$, which agrees with the BET SSAs. The SEMs also do not reveal any particles $>200 \mathrm{~nm}$. In Figure $1 \mathrm{~b}$, the TEM images shows partially crystalline spherical particles. Some necking can be seen between the particles; however, this does not represent the majority of the powder.

\subsection{Tube Extrusion and Burnout}

Through trial and error, we identified a binder, consisting primarily of a polyethylene-vinyl acetate-based hot-melt adhesive, that offers the viscoelastic properties needed to melt extrude powder/binder mixtures (see the Experimental Section). The adhesive materials were characterized by thermogravimetric analysis (TGA) and solvent solubility and were found not to contain any insoluble inorganic materials; therefore, no ceramic residue would be retained following binder burnout.

Tubes could be extruded up to $1 \mathrm{~m}$ in length with typical diameters of $10 \mathrm{~mm}$ with $0.7 \mathrm{~mm}$-thick walls. The tube lengths were limited only by the volume of melt loaded into the die.

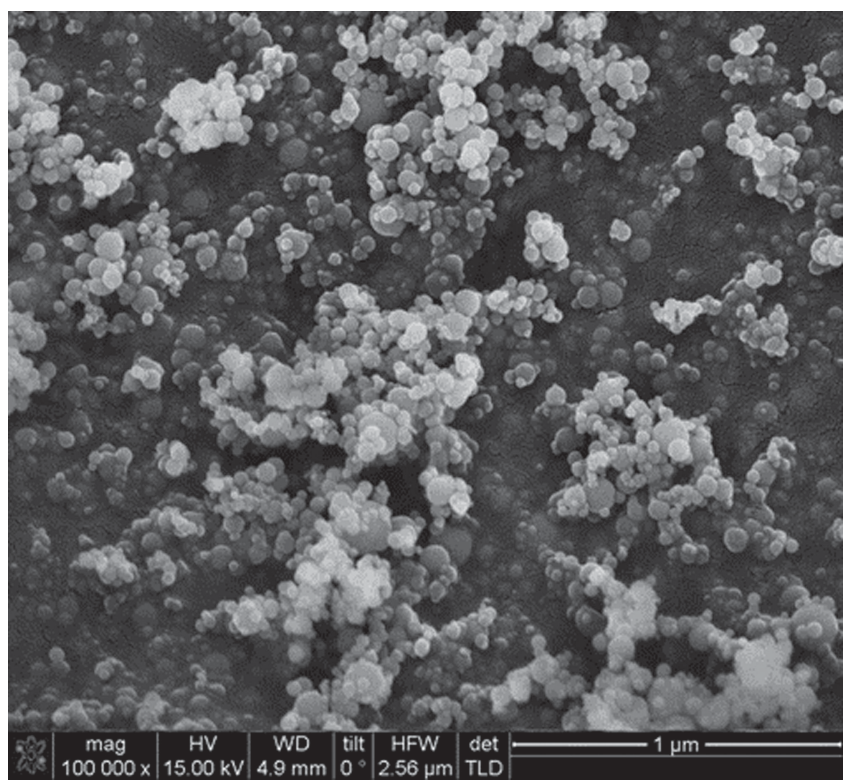

Figure 2. Representative SEM images of as-produced LF-FSP $\mathrm{Y}_{2} \mathrm{O}_{3}$. 


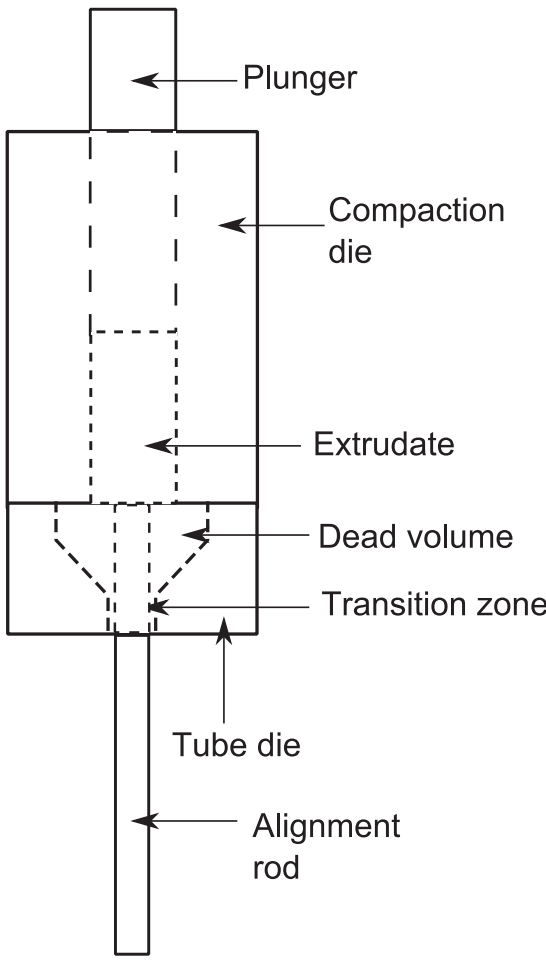

Figure 3. Schematic of extruder and spider extrusion die.

Figure 3 provides a schematic of the extruder and spider extrusion die. Thermoplastic melts for extrusion were loaded at 50 vol\% powder, corresponding to an approximate solids loading of 82 wt\%. Powder loadings < 45 vol\% were insufficient to maintain a tubular geometry through burnout. Thermoplastic melts with higher ceramic loading were difficult to extrude into defect free bodies. The high amounts of binder required a first burnout step in dry $\mathrm{N}_{2}$, followed by dry air and then $\mathrm{O}_{2}$. The final $\mathrm{O}_{2}$ burnout was performed at $800{ }^{\circ} \mathrm{C}$ to impart mechanical strength to the debindered bodies.

Figure 4a shows cross-sections of an as-extruded tube, a fully debindered tube, and a tube sintered to $95 \%$ TD. Cross-sectional geometry was maintained from the as-extruded tubes through to the final sintered product. Figure $4 \mathrm{~b}$ provides a view of longer extruded sections, along with a debindered tube and a sintered tube. Some deviations from linearity along the tube axis are seen in the as-extruded tubes. However, the extrusion process did not use a guide rod, which is expected to improve overall straightness.

\subsection{Tube Sintering}

Two different routes to $95 \%$ dense YAG tubes were examined to ensure that one processing approach did not favor one set of materials over the other. Thus, reactive sintering of $\mathrm{Al}_{2} \mathrm{O}_{3}$ and $\mathrm{Y}_{2} \mathrm{O}_{3}$ and sintering of hex- $\mathrm{Y}_{3} \mathrm{Al}_{5} \mathrm{O}_{12}$ tubes were run under a $10^{-3-}-10^{-4}$ Torr vacuum. All samples were first heated in vacuum at $1000{ }^{\circ} \mathrm{C}$ for $2 \mathrm{~h}$, which has previously been found to improve pore size distributions. ${ }^{[25]}$

One processing approach followed the two-step method of Chen and Wang that involves ramping to a peak temperature

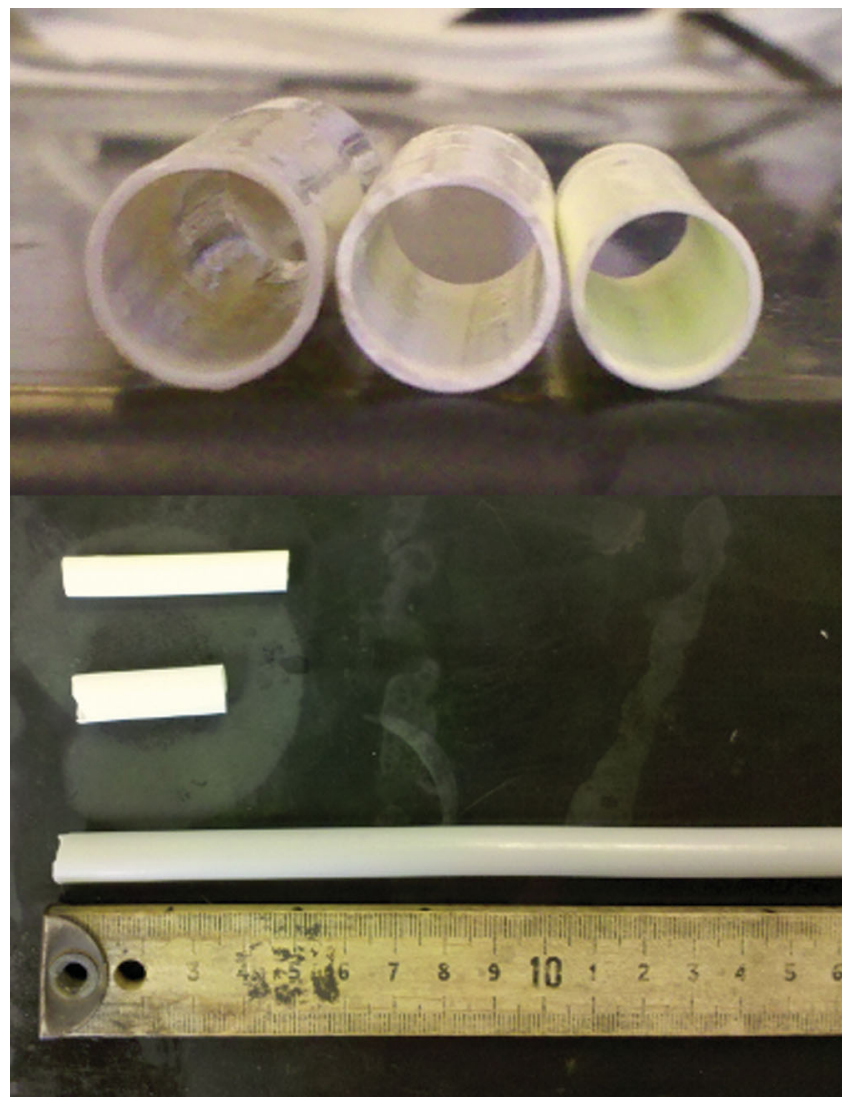

Figure 4. a) Optical photograph of tubes, from left to right: as-extruded, burnt-out, and 95\% TD. b) Images of tubes, from top to bottom: 95\% TD sintered, burned-out, and as-extruded.

followed by a long isothermal hold at a lower temperature. ${ }^{[26]}$ Two-step sintering is an effective way to minimize grain size, and has been used successfully in processing YAG. ${ }^{[27]}$ Reactive $\mathrm{Y}_{2} \mathrm{O}_{3}-\mathrm{Al}_{2} \mathrm{O}_{3}$ tubes were sintered using two-step sintering with an initial peak temperature of $1500{ }^{\circ} \mathrm{C}$, followed by isothermal holds of $20-30 \mathrm{~h}$ at $1300{ }^{\circ} \mathrm{C}$. Tubes sintered to a final density of at least $96 \%$ TD after $30 \mathrm{~h}$ holds.

Ball-milled, reactive $\mathrm{Y}_{2} \mathrm{O}_{3}-\mathrm{Al}_{2} \mathrm{O}_{3}$ pellets of the same composition did not sinter well below $1500{ }^{\circ} \mathrm{C}$. This difference in sintering behavior may arise because of the intensive shear mixing of the thermoplastic mixer or simply because the binder used in forming the pellets was simply polyethylene oxide (PEO) rather than the vinylacetate polymer. The microstructure shown in Figure $\mathbf{5}$ is typical of reactive sintered YAG and offers grain sizes of $500 \pm 30 \mathrm{~nm}$ by lineal intercept.

Hex- $\mathrm{Y}_{3} \mathrm{Al}_{5} \mathrm{O}_{12}$ powder tubes sinter only to $\approx 70 \%$ TD using the same two-step scheme (Figure 6a) and were only found to sinter on heating to $1500{ }^{\circ} \mathrm{C}$ for extended periods (Figure 6b). After $35 \mathrm{~h}$ at $1500^{\circ} \mathrm{C}$ in vacuum, sintering of hex $-\mathrm{Y}_{3} \mathrm{Al}_{5} \mathrm{O}_{12}$ composition tubes stalled at $\approx 93 \%$ TD. Further sintering at $1600{ }^{\circ} \mathrm{C} / 5 \mathrm{~h}$ /air brought the tubes to $98 \%$ TD with typical microstructures as shown in Figure 6b. This microstructure is characterized by a distribution of grains much larger $(3-5 \mu \mathrm{m})$ than seen in Figure 5 . For optical applications, subsequent hot isotatic pressing is mandated by the need to eliminate the remaining closed porosity. ${ }^{[2]}$ 


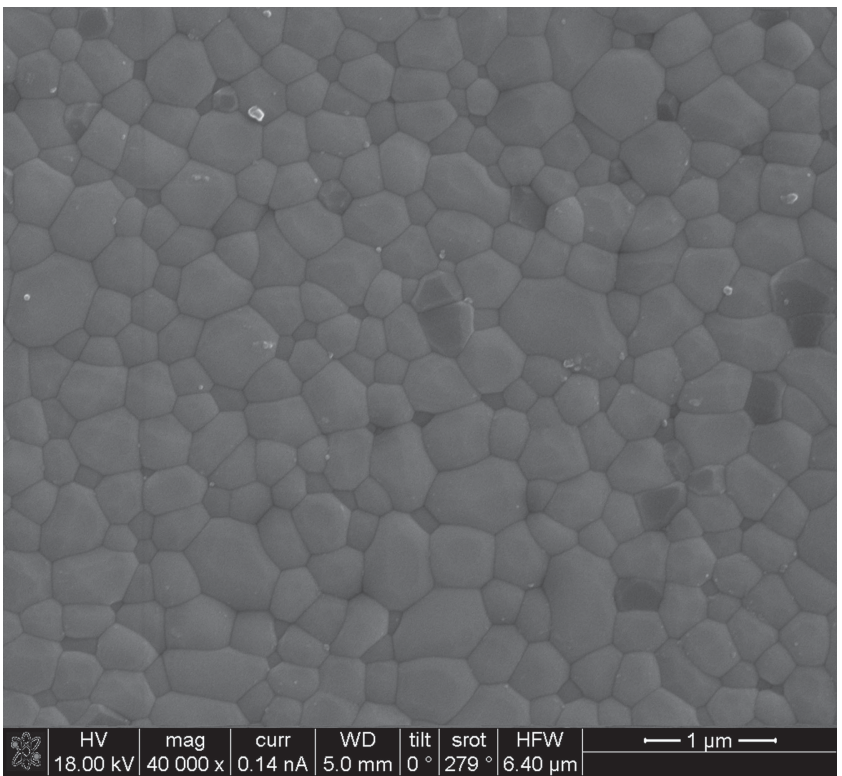

Figure 5. $\mathrm{Y}_{2} \mathrm{O}_{3}-\mathrm{Al}_{2} \mathrm{O}_{3}$ tube fracture surface SEM image; two-step heated to $1500 / 1300{ }^{\circ} \mathrm{C}(96 \%$ TD).

Figure 7 and Figure 8 provide time/temperature XRDs for hex- $\mathrm{Y}_{3} \mathrm{Al}_{5} \mathrm{O}_{12}$ and $\mathrm{Y}_{2} \mathrm{O}_{3}-\mathrm{Al}_{2} \mathrm{O}_{3}$ powders mixtures, respectively. As-produced hex- $\mathrm{Y}_{3} \mathrm{Al}_{5} \mathrm{O}_{12}$ powders show a diffraction pattern indicating monoclinc yttrium aluminate (YAM), $\mathrm{Y}_{4} \mathrm{Al}_{2} \mathrm{O}_{9}$, as well as a pattern similar to hexagonal $\mathrm{YAlO}_{3}$, but actually the hexagonal $\mathrm{Y}_{3} \mathrm{Al}_{5} \mathrm{O}_{12}$ phase. ${ }^{[16]} \mathrm{YAM}$, hexagonal- $\mathrm{Y}_{3} \mathrm{Al}_{5} \mathrm{O}_{12}$, and $\mathrm{YAlO}_{3}$ (YAP) phases are commonly present in nano-YAG synthesized by a variety of solution-based processes. ${ }^{[28]}$ After $3 \mathrm{~h}$ at $1100{ }^{\circ} \mathrm{C}$, the powders transform fully to YAG. $\mathrm{Y}_{2} \mathrm{O}_{3}-\mathrm{Al}_{2} \mathrm{O}_{3}$ reactive sintering consists of a mixture of $\mathrm{Y}_{2} \mathrm{O}_{3}$ and $\delta-\mathrm{Al}_{2} \mathrm{O}_{3}$ at low temperatures. Heating to $1100{ }^{\circ} \mathrm{C}$ causes formation of YAP and YAM. Then at $1200{ }^{\circ} \mathrm{C} / 3 \mathrm{~h}$, the $\mathrm{Y}_{2} \mathrm{O}_{3}-\mathrm{Al}_{2} \mathrm{O}_{3}$ powders fully transform into YAG.

As previously shown, the activation energy for the transformation of the hexagonal phase to YAG is $\approx 110 \mathrm{~kJ} / \mathrm{mol}$, compared to $550 \mathrm{~kJ} / \mathrm{mol}$ for the transformation of $\mathrm{YAlO}_{3}$ to YAG. This accounts for the full transformation of the hexagonal powders at $1100{ }^{\circ} \mathrm{C} / 3$ h. ${ }^{[24,29]}$ Differential thermal analysis (DTA)

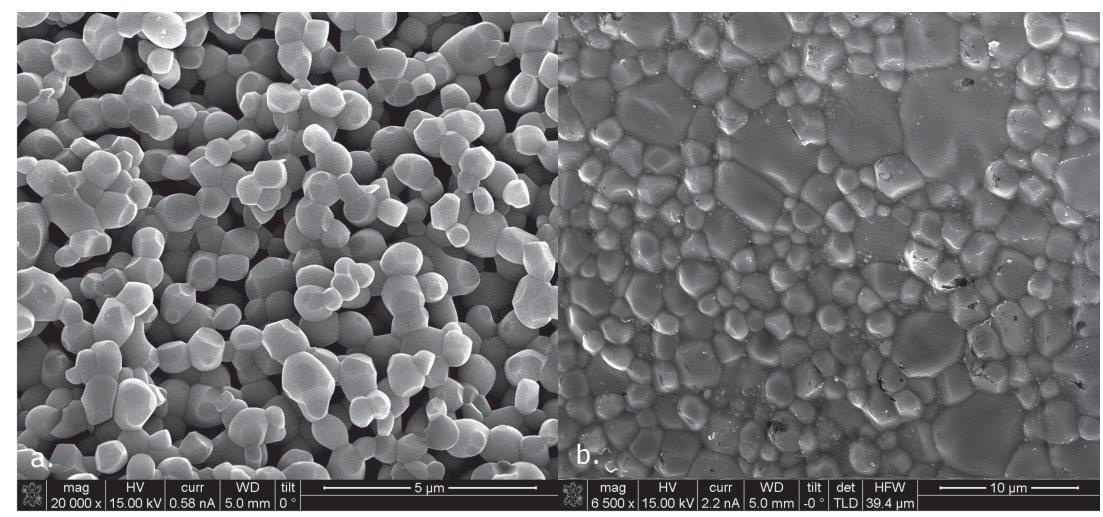

Figure 6. SEM images of $\mathrm{Y}_{3} \mathrm{Al}_{5} \mathrm{O}_{12}$ composition. a) Tube surface two-step heated to $1500 / 1300^{\circ} \mathrm{C}$ (70\% TD); b) fracture surface at $98 \%$ TD after heating to $1600^{\circ} \mathrm{C} / 5 \mathrm{~h} /$ air.

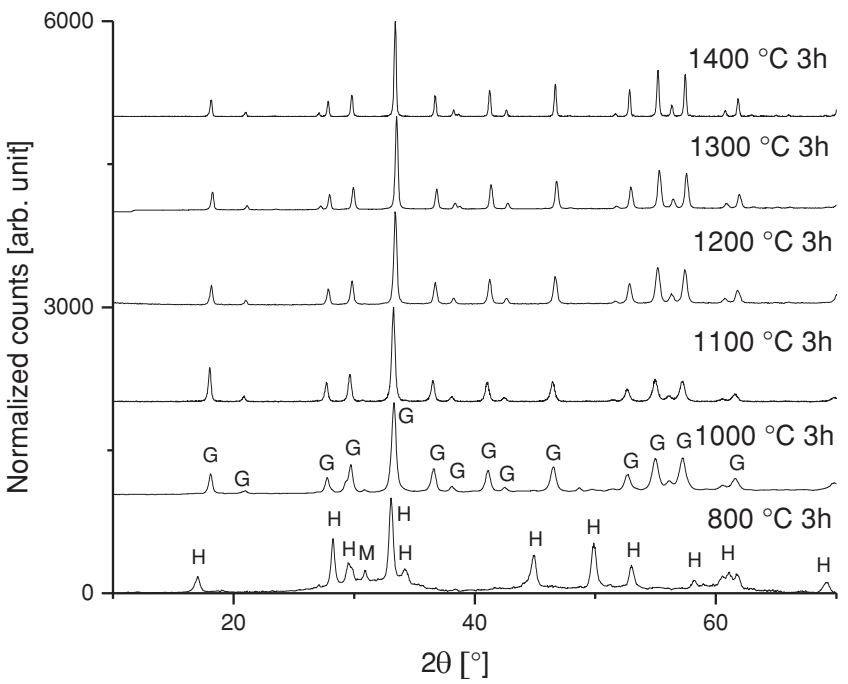

Figure 7. XRDs of $\mathrm{Y}_{3} \mathrm{Al}_{5} \mathrm{O}_{12}$ ground tubes on sintering for $3 \mathrm{~h}$ at 800-1400 ${ }^{\circ} \mathrm{C}$. (H-Hexagonal $\mathrm{YAlO}_{3}, \mathrm{M}-\mathrm{Y}_{4} \mathrm{Al}_{2} \mathrm{O}_{9}, \mathrm{G}-\mathrm{Y}_{3} \mathrm{Al}_{5} \mathrm{O}_{12}$ garnet).

traces for both $\mathrm{Y}_{3} \mathrm{Al}_{5} \mathrm{O}_{12}$ and $\mathrm{Y}_{2} \mathrm{O}_{3}-\mathrm{Al}_{2} \mathrm{O}_{3}$ (see the Supporting Information) give the phase transformation temperatures shown in Table 2.

Although both samples show similar YAG nucleation temperatures, the XRD patterns suggest different rates to full transformation, likely determined by the diffusion distances. The differences in densification rates between the reactive and exact composition samples is unusual. One explanation is that densification occurs prior to full phase transformation in the $\mathrm{Y}_{2} \mathrm{O}_{3}-\mathrm{Al}_{2} \mathrm{O}_{3}$ system. At a low temperature, the hex-YAG powders were shown by XRD to fully transform to YAG. As such, any sintering can be explained mechanistically as that of YAG. In YAG, anion diffusion has been shown to be the rate-determing species for lattice diffusion. ${ }^{[30]}$ For the reactive sintering case, the mechanics are more complicated. $\mathrm{O}$ is the rate-limiting species in $\mathrm{Al}_{2} \mathrm{O}_{3}$, and $\mathrm{Y}$ is the rate-limiting species in $\mathrm{Y}_{2} \mathrm{O}_{3} \cdot{ }^{[30,31]}$ Diffusional couples of $\mathrm{Al}_{2} \mathrm{O}_{3}$ and $\mathrm{Y}_{2} \mathrm{O}_{3}$ have shown that the reaction occurs when $\mathrm{Al}$ diffuses into the $\mathrm{Y}_{2} \mathrm{O}_{3}$ lattice. ${ }^{[32]}$ As such, the reaction between $\mathrm{Al}_{2} \mathrm{O}_{3}$ and $\mathrm{Y}_{2} \mathrm{O}_{3}$ should produce yttrium-rich phases before YAG stoichiometry is reached. This is reflected by the XRD patterns from the reactive $\mathrm{Y}_{2} \mathrm{O}_{3}-\mathrm{Al}_{2} \mathrm{O}_{3}$ tubes, where yttrium-rich YAP and YAM are formed prior to transformation to YAG. It should be noted that the lattice mobility of $\mathrm{Al}$ in $\mathrm{Y}_{2} \mathrm{O}_{3}$ is five times that of $\mathrm{Al}$ in YAG. ${ }^{[32]}$

Thus, there is a basis to claim that low temperture densification of reactive $\mathrm{Y}_{2} \mathrm{O}_{3}-\mathrm{Al}_{2} \mathrm{O}_{3}$ powders represents densification seen prior to full transformation to the garnet phase. However, diffusion in some yttrium aluminate phases (YAP, YAM) has not been well characterized. As such, a number of phases with different diffusion mechanisms may exist at any one time in the sintering process.

Contamination may provide an alternate explanation for the sintering behavior seen 


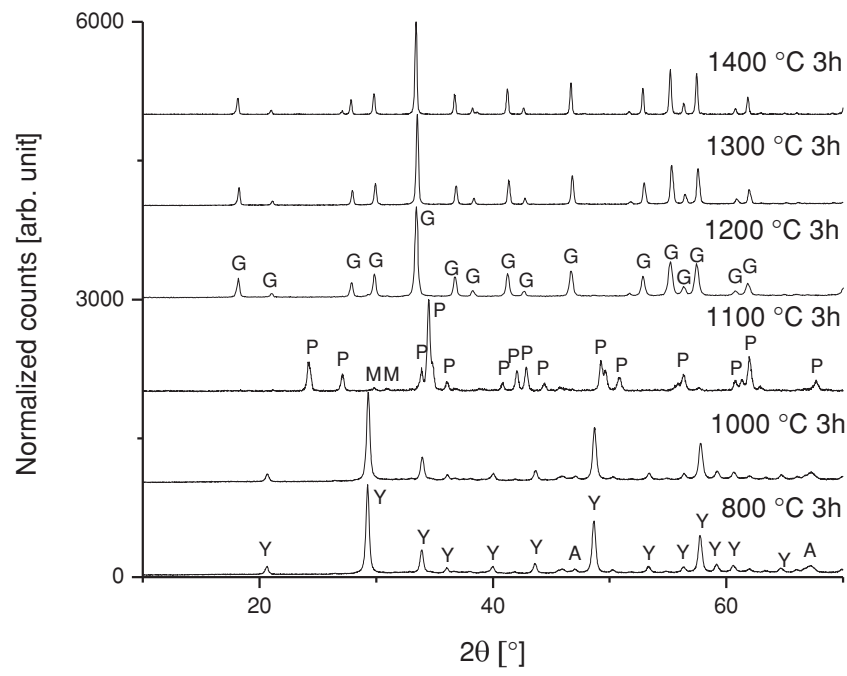

Figure 8. $X R D s$ for $\mathrm{Y}_{2} \mathrm{O}_{3}-\mathrm{Al}_{2} \mathrm{O}_{3}$ ground tubes on sintering for $3 \mathrm{~h}$ at 800-1400 ${ }^{\circ} \mathrm{C}$. (Y-Y ${ }_{2} \mathrm{O}_{3}, \mathrm{~A}$-transtion- $\left.\mathrm{Al}_{2} \mathrm{O}_{3}, \mathrm{P}-\mathrm{YAP}, \mathrm{M}-\mathrm{YAM}\right)$.

in the $\mathrm{Y}_{2} \mathrm{O}_{3}-\mathrm{Al}_{2} \mathrm{O}_{3}$ system. Indeed, the micrographs shown in Figure 5 reveal small numbers of darker grains that result from less electron dense materials. Element mapping studies (Figure S3) suggest that these darker grains are primarily aluminum with little or no yttrium, although we see no evidence of $\alpha-\mathrm{Al}_{2} \mathrm{O}_{3}$ in any XRD studies. This suggests the presence of a small amount of a secondary phase; however, it is not clear if this is responsible for the difference in sintering behavior. For 50 vol\% $\mathrm{Al}_{2} \mathrm{O}_{3}-\mathrm{YAG}$ composites, Palmero et al. found a reduction in sintering temperature from $1600^{\circ} \mathrm{C}$ to as low as $1370{ }^{\circ} \mathrm{C}$ with mechanical activation of powders through ball milling and an optimized pre-calcination step. ${ }^{[33]}$ In another study, Palmero et al. found a $100{ }^{\circ} \mathrm{C}$ lower onset of sintering in 5 vol\% YAG in $\mathrm{Al}_{2} \mathrm{O}_{3} \cdot{ }^{[34]}$ These studies provide a possible explanation for the low-temperature sintering behavior seen here, but the high $\mathrm{Al}_{2} \mathrm{O}_{3}$ contents studied preclude a direct correlation to our work. However, if it is the basis for rapid sintering, then this represents an alternative to the use of $\mathrm{SiO}_{2}$ as a sintering aid in the generation of transparent YAG materials. Clearly future studies should focus on exploring the effects of different excesses of $\mathrm{Al}_{2} \mathrm{O}_{3}$.

A referee has pointed out that the presence of even small amounts of a second phase such as $\mathrm{Al}_{2} \mathrm{O}_{3}$ would preclude the use of these materials for laser applications. It is important to point out to the community that this may not be the case.

Light scattering takes place when there are density or index changes on the scale of the wavelength of light. For second phase inclusions that are much smaller than the wavelengths of emitted or transmitted light, their grain boundary
Table 2. DTA phase formation temperatures for $\mathrm{Y}_{3} \mathrm{Al}_{5} \mathrm{O}_{12}$ and $\mathrm{Y}_{2} \mathrm{O}_{3}-$ $\mathrm{Al}_{2} \mathrm{O}_{3}$ samples.

\begin{tabular}{lcc}
\hline Material & \multicolumn{2}{c}{ Phase formed } \\
\cline { 2 - 3 } & YAP, YAM & YAG \\
\hline $\mathrm{Y}_{2} \mathrm{O}_{3}-\mathrm{Al}_{2} \mathrm{O}_{3}$ & $1160^{\circ} \mathrm{C}$ & $1307^{\circ} \mathrm{C}$ \\
$\mathrm{Y}_{3} \mathrm{Al}_{5} \mathrm{O}_{12}$ & $915^{\circ} \mathrm{C}$ & $1061^{\circ} \mathrm{C}$ \\
\hline
\end{tabular}

contributions to scattering are expected to scale with dimensions: meaning they will go to zero as grain boundary surface area/particle goes effectively to zero.

Furthermore, substitutional (ion) impurities do not degrade optical performance until their concentration becomes very high and their distribution becomes sufficiently inhomogeneous to introduce density or index fluctuations on the scale of a wavelength.

While the above has not been studied extensively and remains to some extent conjecture, it is in keeping with recent work by Krell et al who explored the relationship between Mie scattering from pores as a function of pore size and wavelength of incident light finding that smaller pores contribute little or nothing to scattering at longer wavelengths. ${ }^{[35]}$ Thus, scattering from second phases would be expected to follow the same behavior.

\subsection{Dilatometry Studies}

Dilatometry studies were conducted to follow densification for both systems. Powder compacts (pellets) were pressed, cold isostatic pressed (CIPped) and debindered to provide samples for the dilatometry studies (see Figure 9 and the Experimental Section). There is considerable contrast between the

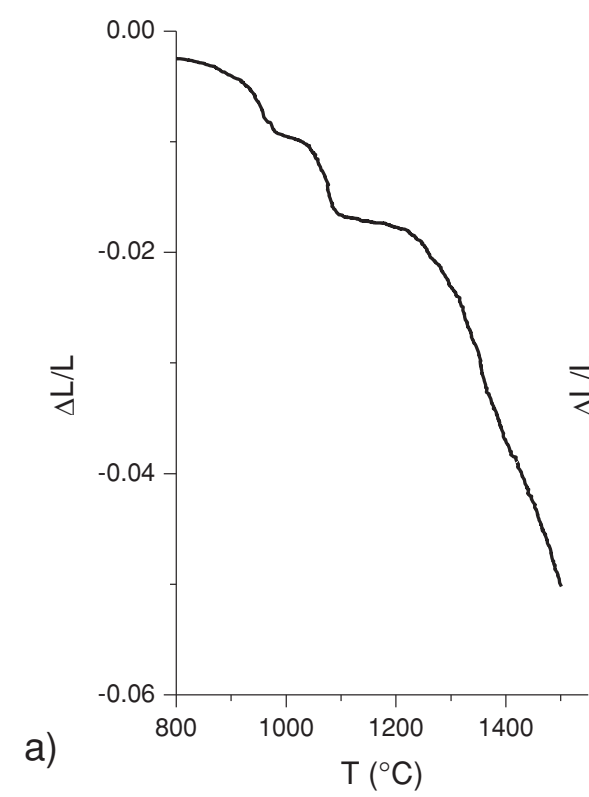

Figure 9. Dilatometry traces of pellets (after debindering at $800{ }^{\circ} \mathrm{C}$ ) of a) $\mathrm{Y}_{3} \mathrm{Al}_{5} \mathrm{O}_{12}$ at 5 and $10{ }^{\circ} \mathrm{C} / \mathrm{min} / \mathrm{air}$; b) $3 \mathrm{Y}_{2} \mathrm{O}_{3}: 5 \delta-\mathrm{Al}_{2} \mathrm{O}_{3}$, heated at $10{ }^{\circ} \mathrm{C} / \mathrm{min} /$ air to $1500{ }^{\circ} \mathrm{C}, 1300{ }^{\circ} \mathrm{C}$ for $3 \mathrm{~h}$ in vacuum. 
two systems. Early densification regions shown in Figure 9a for the hex- $\mathrm{Y}_{3} \mathrm{Al}_{5} \mathrm{O}_{12}$ powders $\left(900-1100{ }^{\circ} \mathrm{C}\right)$ likely result from crystallization of the YAP,YAM, and YAG phases (based on the SEM image in Figure 6a and XRDs shown in Figure 7). Thereafter, densification is slow because of the diffusion rates in YAG, as previously discussed. Indeed, as we have reported elsewhere, the only way to get high-density, relatively fine-grained YAG is to sinter at very high heating rates (up to $30^{\circ} \mathrm{C} / \mathrm{min}$ ). ${ }^{[36]}$

In contrast, $3 \mathrm{Y}_{2} \mathrm{O}_{3}: 5 \delta-\mathrm{Al}_{2} \mathrm{O}_{3}$ densifies rapidly beginning at $1100-1150{ }^{\circ} \mathrm{C}$ then densifying more slowly, as shown in Figure 9b. The likeliest explanation is that the YAG phase forms with sintering but it is not complete even on heating to $1500{ }^{\circ} \mathrm{C}$ briefly. This permits relatively rapid densification in time frames and at temperatures well below those needed to fully densify the atomically mixed $\mathrm{Y}_{3} \mathrm{Al}_{5} \mathrm{O}_{12}$ materials. This is again quite contrary to the maxim that atomic mixing should provide optimal processing of ceramic materials.

\subsection{Tube Processing}

Figure 10a is an optical micrograph of a $98 \%$ TD sintered tube $\left(1600{ }^{\circ} \mathrm{C} / 5 \mathrm{~h} /\right.$ air $)$ that is straight and has a nearly circular crosssection (Figure 10b). Samples were cut from $1 \mathrm{~m}$-long extruded tubes to simplify processing. Figure $\mathbf{1 1}$ shows that the tube is translucent, retaining a bluish tint, assumed to originate from contaminants in the original powder or from shear mixing and extrusion.

\section{Conclusions}

The work described above provides a rare example of thermoplastic extrusion and processing of nanooxide powders to high density ceramic tubes. More importantly it provides an example that contrasts greatly with the general maxim that atomic mixing (bottom-up approach) offers superior opportunities to control time, temperature and rates of densification in processing ceramic materials. In this paper, a single phase, atomically mixed hex- $\mathrm{Y}_{3} \mathrm{Al}_{5} \mathrm{O}_{12}$ nanopowder crystallizes rapidly to YAG faster than it densifies. In contrast a shear mixed $3 \mathrm{Y}_{2} \mathrm{O}_{3}: 5 \delta-\mathrm{Al}_{2} \mathrm{O}_{3}$ set of nanopowders, where the compositional

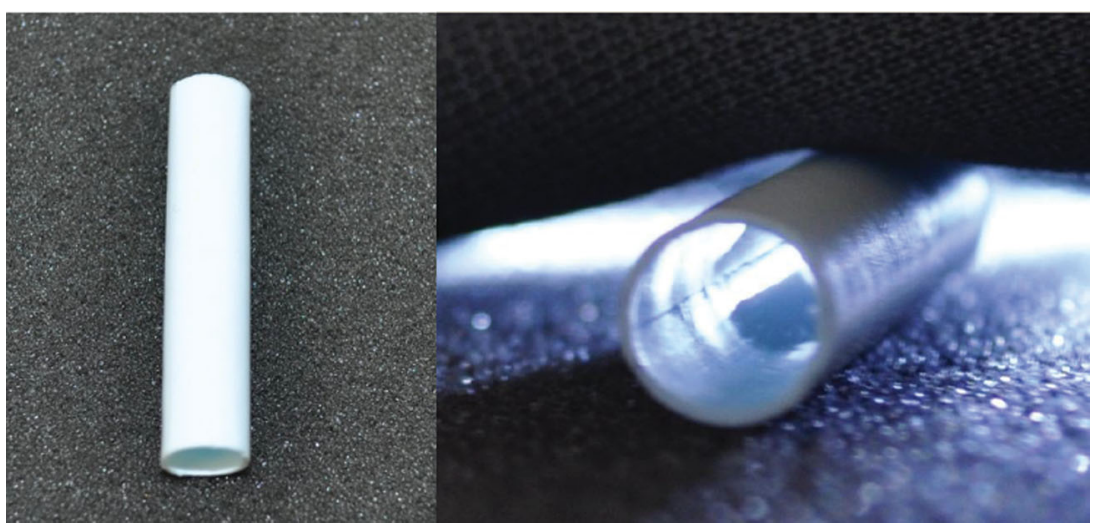

Figure 10. Optical micrograph of sintered $98 \% \mathrm{TD}_{3} \mathrm{Al}_{5} \mathrm{O}_{12}$ composition tube with excellent dimensional uniformity.

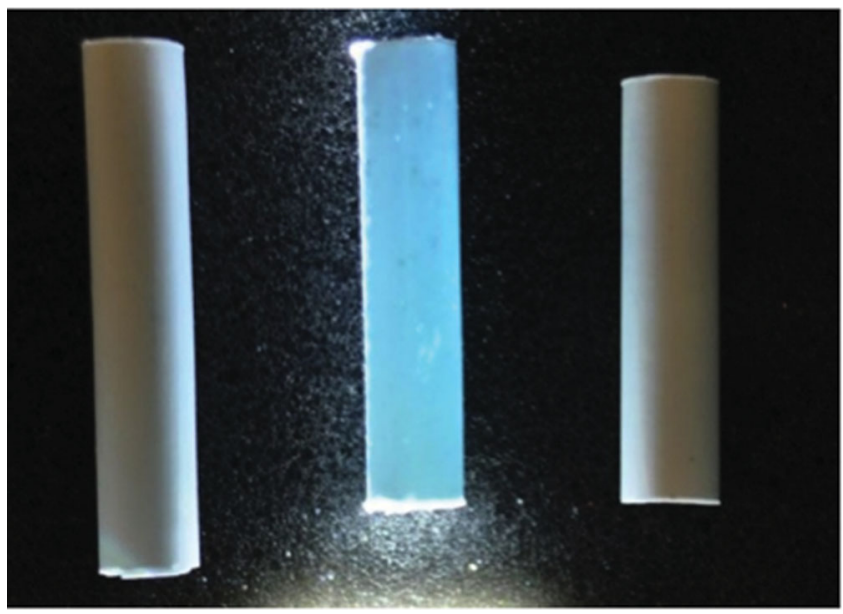

Figure 11. Optical micrograph of sintered, $98 \% \mathrm{TD}_{3} \mathrm{Al}_{5} \mathrm{O}_{12}$ composition tube. The light shining through the sample gives an idea of the translucency.

homogeneity is closer to submicron volumes, sinters much faster because densification occurs much faster than diffusion leading to the formation of the final stoichiometric YAG phase. This work contrasts with an upcoming paper in which phase separation occurs much faster than densification leading to equivalent submicron compositional uniformity prior to processes that result in full densification.

It should be noted that our goal was to achieve densities $>95 \%$ of theory as this represents a practical objective of researchers exploring densification mechanisms and routes to optimizing such processes.

\section{Experimental Section}

Materials: Yttrium propionate was synthesized through the reaction of yttrium carbonate (PIDC, Ann Arbor, MI) with propionic acid. Anhydrous ethanol (Decon Labs (King of Prussia, PA) and Nanotek $\gamma$ $\mathrm{Al}_{2} \mathrm{O}_{3}$ (Nanophase Technologies, Chicago, IL) were used in this work, along with bicine, polyethylene glycol, and stearic acid (Sigma-Aldrich). Alumatrane was synthesized as described elsewhere. ${ }^{[37]}$ Nanotek $\gamma-\mathrm{Al}_{2} \mathrm{O}_{3}$ was received as a gift. Ethylene vinyl acetate hot melt adhesive was purchased from standard sources.

LF-FSP: Yttrium propionate and alumatrane were used as precursors of $\mathrm{Y}_{2} \mathrm{O}_{3}$ and $\mathrm{Al}_{2} \mathrm{O}_{3}$, respectively. Ethanol solutions at less than $5 \mathrm{wt} \%$ ceramic loading were aerosolized using $\mathrm{O}_{2}$ at $80 \mathrm{psi}$ and combusted, producing oxide nanopowders, either $\mathrm{Y}_{2} \mathrm{O}_{3}$ or YAC composition that were collected downstream at 50-100 g/h. The resultant powders were evalulated using nitrogen BET analysis for surface area measurements and SEM and TEM measurements.

Powder Processing: For reactive sintering, approximately $60 \mathrm{~g}$ of as-shot LF-FSP $\mathrm{Y}_{2} \mathrm{O}_{3}$ was added to $750 \mathrm{~mL}$ of ethanol, with $2 \mathrm{wt} \%$ bicine as a dispersant. The suspension was ultrasonicated for 20 min using a Vibracell VC-505 ultrasonic horn (Sonics \& Materials, Newtown, CT) at $100 \mathrm{~W}$ of power. After a $24 \mathrm{~h}$ settling period, the supernatant was decanted and dried. The same process was repeated using $60 \mathrm{~g}$ of NanoTek $\mathrm{Al}_{2} \mathrm{O}_{3}$. The dried 
powders were mixed in a $3: 5$ stoichiometric ratio, and added to $750 \mathrm{~mL}$ of ethanol. The suspension was ultrasonicated for $20 \mathrm{~min}$ at $100 \mathrm{~W}$, and dried. The resulting powders were then used for thermoplastic processing. The as-produced YAG composition powders were processed using the same conditions.

Shear Mixing: Thermoplastic-ceramic powder extrusion mixtures were produced at volumes of $42 \mathrm{~cm}^{3}$. The mixture consisted of 1 vol\% polyethylene glycol with a $M_{n}=3400,1$ vol\% stearic acid, 3 vol\% heavy mineral oil, 48-50 vol\% nanopowder, and the remainder was an ethylene vinyl acetate based hot-melt adhesive (3M \#3792LM B).

Powders were mixed on a Brabender Plasti-Corder 2100 (C.W. Brabender, Hackensack, N.J.) twin-screw shear mixer. The mixing chamber was preheated to $120{ }^{\circ} \mathrm{C}$. Approximately $80 \%$ of the hot-melt adhesive was added to the mixing chamber and allowed to melt. With the shear mixer running at approximately $60 \mathrm{rpm}$, the powder was slowly added. Powders were allowed to mix in fully before more powder was added. Upon saturation of the hot-melt adhesive with powder, the final amount of hot-melt adhesive was added. After approximately $90 \%$ of the powder had been added to the thermoplastic melt, the minor components were added. Following the full addition of all the of powder, the thermoplastic ceramic melt was mixed for approximately $15 \mathrm{~min}$ at $60 \mathrm{rpm}$. The mixer was stopped, and the melt was cooled before it was removed from the chamber. The hardened melt was granulated, and slowly added back into the chamber at $120^{\circ} \mathrm{C}$ to ensure complete homogeneity of the melt. The powder was mixed at $60 \mathrm{rpm}$ for an additional $30 \mathrm{~min}$. The cooled melt was manually granulated prior to extrusion.

Extrusion: Prior to extrusion, the thermoplastic-ceramic mixture was degassed in a vacuum oven at $110^{\circ} \mathrm{C}$ for $2 \mathrm{~h}$. The vacuum level was estimated to be around $10^{-3}$ Torr. Extrusion was performed on a Bradford Small Scale Extrusion Unit (Bradford University Research, Ltd., West Yorkshire, UK) ram extrusion machine using a spider die. The 31 $\mathrm{mm}$ diameter extrusion die was preheated to $140^{\circ} \mathrm{C}$, and the granulated thermoplastic-ceramic mixture was added to the die. The bottom of the die was blocked, and the ram was pressed to a pressure of $2.3 \mathrm{MPa}$. The die was cooled to $50^{\circ} \mathrm{C}$, and the stop was removed from the end of the die. A smaller heating mantle was then applied to the spider region of the die. The spider was heated to $120-130^{\circ} \mathrm{C}$, and tubes were extruded at typical rates of $2 \mathrm{~mm} \mathrm{~min} \mathrm{~min}^{-1}$, with die pressures averaging $1 \mathrm{MPa}$. Dimensionally uniform tubes up to $0.7 \mathrm{~m}$ in length were extruded.

Burnout: Tubes were burned out at $3^{\circ} \mathrm{C} \mathrm{min}-1$ to $400{ }^{\circ} \mathrm{C}$ for $4 \mathrm{~h}$ in dry $\mathrm{N}_{2}$. Tubes were then burned out at $3{ }^{\circ} \mathrm{C} \mathrm{min}^{-1}$ to $600{ }^{\circ} \mathrm{C}$ for $4 \mathrm{~h}$ in dry air. Tubes were then burnt out to $800^{\circ} \mathrm{C}$ for $3 \mathrm{~h}$ under flowing $\mathrm{O}_{2}$. Gas flow rates were kept constant at $50 \mathrm{~mL} / \mathrm{min}$.

Sintering: Tubes were sintered in rough vacuum in a MTI GSL-1600X tube furnace up to $1500{ }^{\circ} \mathrm{C}$ or in a BlueM muffle furnace for temperatures above $1500{ }^{\circ} \mathrm{C}$. Two different sintering schedules were investigated, a two-step $1500{ }^{\circ} \mathrm{C} 0 \mathrm{~h}$ peak with $20-30 \mathrm{~h}$ holds at $1300{ }^{\circ} \mathrm{C}$, or up to $35 \mathrm{~h}$ holds at $1500^{\circ} \mathrm{C}$ followed by $5 \mathrm{~h}$ at $1600^{\circ} \mathrm{C}$.

Density Measurements: Sample densities were tracked during sintering by monitoring the average tube diameter, which was converted into a linear shrinkage value that was correlated to the final density. Final densities were calculated using Archimedes density measurements. Samples were first boiled in deionized $\mathrm{H}_{2} \mathrm{O}$ for $5 \mathrm{~h}$ and left to sit for $24 \mathrm{~h}$ in $\mathrm{H}_{2} \mathrm{O}$ at room temperature. Measurements were performed using an Archimedes density kit for a Ohaus Voyager Pro balance, with a sensitivity of $0.1 \mathrm{mg}$. Dry masses were determined after heating the samples to $110^{\circ} \mathrm{C}$ for $24 \mathrm{~h}$. All densities were compared to that of YAG, $4.55 \mathrm{~g} \mathrm{~cm}^{-3}$.

Analytical Techniques: X-ray Diffraction (XRD) was performed on a high-intensity Rigaku rotating anode at $40 \mathrm{kV}$ and $100 \mathrm{~mA}$ (Rigaku USA, The Woodlands, TX). Sample scans were taken from $10-70^{\circ} 2 \theta$ with $0.02^{\circ}$ intervals and scanned at a rate of $2.0^{\circ} 2 \theta / \mathrm{min}$. X-ray patterns were analyzed using JADE 10.0. X-ray diffaction was performed on as-produced and as-recieved powders, as well as ground sintered tubes. Scanning electron microscope measurements were performed using a FEI Nova Nanolab dualbeam SEM/FIB (FEI Corporation, Hillsboro, OR) equipped with a Schottky FEG. Powders were dropped onto conductive copper tape on a sample stub. Transmission electron microscope measurements were performed on a JEOL 3011 HREM (JEOL Ltd., Tokyo, Japan) at $300 \mathrm{kV}$. Powders were dispersed in ethanol and wicked through a holey carbon grid. Surface area analysis (SSA) results were obtained on a Micromeritics ASAP 2020 sorption analyzer (Norcross, GA). Samples were degassed for $8 \mathrm{~h}$ at $400^{\circ} \mathrm{C}$. Analysis was conducted on $\sim 200 \mathrm{mg}$ samples at $77 \mathrm{~K}$ with $\mathrm{N}_{2}$ adsorbate gas. SSA's were calculated using an 11 point BET method with relative pressures from 0.05-0.35. Simultaneous TGA-DTA was performed on a Q600 TGA-DTA instrument (TA Instruments, Inc., New Castle, DE). Measurements were taken under $60 \mathrm{~mL} \mathrm{~min}{ }^{-1}$ of compressed extra dry air. Samples (20-40 mg) were pressed in a $3 \mathrm{~mm}$ die and placed in an alumina sample pan. The reference pan was alumina. Samples were heated at $10^{\circ} \mathrm{C} \mathrm{min}^{-1}$ to $1400{ }^{\circ} \mathrm{C}$.

\section{Supporting Information}

Supporting Information is available from the Wiley Online Library or from the author.

\section{Acknowledgements}

The authors gratefully acknowledge the support of UES, Inc. and the Air Force Office of Scientific Research as subcontract on AFOSR Contract FA9550-09-C 0054. The authors also acknowledge partial support from NSF through DMR 1105361. Finally, the authors thank Drs. Kristin Keller and Heedong Lee for their significant input in this work and for providing the images used for Figures 10 and 11. R.M.L. would like to thank the Technion, Haifa, Israel for a Lady Davis Fellowship where portions of this manuscript were written.

Received: April 16, 2013

Revised: July 18, 2013

Published online: October 8, 2013

[1] G. C. Wei, J. Phys. D: Appl. Phys. 2005, 38, 3057.

[2] A. Krell, P. Blank, H. Ma, T. Hutzler, M. P. B. van Bruggen, R. Apetz, J. Am. Ceram. Soc. 2003, 86, 12.

[3] H. Yagi, T. Yanagitani, T. Numazawa, K. Ueda, Ceram. Int. 2007, 33, 711.

[4] T.-I. Mah, T. A. Parthasarathy, H. D. Lee, J. Ceram. Proc. Res. 2004, 5, 369.

[5] R. Apetz, M. P. B. van Bruggen, J. Am. Ceram. Soc. 2003, 86, 480.

[6] A. K. Pradhan, K. Zhang, G. B. Loutts, Mater. Res. Bull. 2004, 39, 1291.

[7] A. Ikesue, I. Furusato, K. Kamata, J. Am. Ceram. Soc. 1995, 78, 225.

[8] S. Kochawattana, A. Stevenson, S.-H. Lee, M. Ramirez, V. Gopalan, J. Dumm, V. K. Castillo, G. J. Quarles, G. L. Messing, J. Eur. Ceram. Soc. 2008, 28, 1527.

[9] K. A. Appiagyei, G. L. Messing, J. Q. Dumm, Ceram. Int. 2008, 34, 1309.

[10] M. Trunec, J. Cihlar, S. Diethelm, J. Van Herle, J. Am. Ceram. Soc. 2006, 89, 949 .

[11] R. C. Svedberg, R. K. Sievers, J. F. Ivanenok, T. K. Hunt D. A. Butkiewicz, J. E. Pantolin, K. D. Swift, M. Schuller, M. A. Ryan, AIP Conf. Proc. 1994, 301, 1507

[12] C. Kaya, S. Blackburn, J. Eur. Ceram. Soc. 2004, 24, 3663.

[13] R. M. Laine, R. Baranwal, T. Hinklin, D. Treadwell, A. Sutorik, C. Bickmore, K. Waldner, S. S. Neo, Key Engin. Mater. 1999, 159-160, 17.

[14] T. Hinklin, B. Toury, C. Gervais, F. Babonneau, J. J. Gislason, R. W. Morton, R. M. Laine, Chem. Mater. 2004, 16, 21. 
[15] C. M. Lieber, MRS Bull. 2003, 28, 486.

[16] L. Zhi, K. Müllen, J. Mater. Chem. 2008, 18, 1472.

[17] R. Murugavel, H. G. Walawalkar, M. Dan, H. W. Roesky, C. N. R. Rao, Acc. Chem. Res. 2004, 37, 763.

[18] L. G. Hubert-Pfalzgraf, J. Mater. Chem. 2004, 14, 3113.

[19] W. Lu, C. M. Lieber, Nature Mater. 2007, 6, 841.

[20] J. Binner, B. Vaidhyanathan, J. Eur. Ceram. Soc. 2008, 28, 1329.

[21] R. Ramaseshan, S. Sundarrajan, R. Jose, S. Ramakrishna, J. App. Phys. 2007, 102, 111101

[22] S. Komarneni, J. Mater. Chem. 1992, 2, 1219.

[23] J. Marchal, T. John, R. Baranwal, T. Hinklin, R. M. Laine, Chem. Mater. 2004, 16, 822.

[24] R. M. Laine, J. Marchal, H. Sun, X. Q. Pan, Adv. Mater. 2005, 17, 830.

[25] J. C. Marchal, Ph.D Thesis, University of Michigan, USA 2008.

[26] I.-W. Chen, X.-H. Wang, Nature 2000, 404, 168.
[27] Z.-H. Chen, J.-T. Li, J.-J. Xu, Z-G. Hu, Ceram. Int. 2008, 34, 1709.

[28] S. M. Sim, K. A. Keller, T. I. Mah, J. Mater. Sci. 2000, 35, 713.

[29] R. Chaim, J. Mater. Sci. 2006, 41, 7862.

[30] T. A. Parthasarathy, T.-I. Mah, K. Keller, J. Am. Ceram. Soc. 1992, 75, 1756.

[31] M. F. Berard, D. R. Wilder, J. Appl. Phys. 1963, 34, 2318.

[32] V. B. Glushkova, V. A. Krzhizhanovskaya, O. N. Egorova, Yu. P. Udalov, L. P. Kachalova, Inorg. Mater. 1983, 19, 80.

[33] P. Palmero, A. Simone, C. Esnouf, G. Fantozzi, L. Montanaro, J. Eur. Ceram. Soc. 2006, 26, 941.

[34] P. Palmero, V. Naglieri, J. Chevalier, G. Fantozzi, L. Montanaro, J. Eur. Ceram. Soc. 2009, 29, 59.

[35] A. Krell, K. Waetzig, J. Klimke, J. Eur. Ceram. Soc. 2012, 32, 2887.

[36] Y. Liu, Z.-F. Zhang, J. Halloran, R. M. Laine, J. Am. Ceram. Soc. 1998, 81, 629.

[37] R. Baranwal, M. P. Villar, R. Garcia, R. M. Laine, J. Am. Ceram. Soc. 2001, 84, 951. 